\title{
Greater occipital nerve blockade for cluster headache
}

\author{
MFP Peres, MA Stiles, HC Siow, TD Rozen, WB Young \& SD Silberstein \\ Jefferson Headache Center, Thomas Jefferson University, Philadelphia, PA, USA
}

\section{Cephalalgia}

Peres MFP, Stiles MA, Siow HC, Rozen TD, Young WB \& Silberstein SD. Greater occipital nerve blockade for cluster headache. Cephalalgia 2002; 22:520-522. London. ISSN 0333-1024

Cluster headache is perhaps the most painful of the primary headache disorders. Its treatment includes acute, transitional, and preventive therapy. Despite the availability of many treatments, cluster headache patients can still be difficult to treat. We treated 14 cluster headache patients with greater occipital nerve block as transitional therapy (treatment initiated at the same time as preventive therapy). The mean number of headache-free days was $13.1+23.6$. Four patients $(28.5 \%)$ had a good response, five $(35.7 \%)$ a moderate, and five $(35.7 \%)$ no response. The greater occipital nerve block was well tolerated with no adverse events. Headache intensity, frequency and duration were significantly decreased comparing the week before with the week after the nerve block $(P<0.003, P=0.003, P<0.005$, respectively). Greater occipital nerve blockade is a therapeutic option for the transitional treatment of cluster headache. $\square$ Cluster headache, nerve block, occipital nerve

Stephen D. Silberstein MD, FACP, Jefferson Headache Center, Thomas Jefferson University, Philadelphia, PA, USA. Tel. +12159552243, fax +12159556682,

e-mail Stephen.Silberstein@mail.tju.ed Received 22 October 2001, accepted 15 April 2002

\section{Introduction}

Cluster headache is among the most painful headache disorders. Its medical treatment includes acute, transitional, and preventive therapy. Options for the preventive treatment of cluster headache include verapamil, valproic acid, topiramate, prednisone, methysergide, lithium, melatonin and surgery for refractory patients (1). Cervical nerve blocks have been reported to be effective in cluster headache treatment $(2,3)$.

The greater occipital nerve (GON) blockade could interfere in the trigeminal activity in cluster headache and potentially interrupt the trigeminal autonomic reflex pathway (4). We assessed the effectiveness of GON blockade in cluster headache patients, and suggest its use as a transitional therapy.

\section{Methods}

Fourteen patients (12 men, two women, age range 29-69 years, mean 46.8 years; five chronic, nine episodic cluster) diagnosed with cluster headache according to the International Headache Society (IHS) diagnostic criteria (3) received a GON block ipsilateral to the side of head pain. The main aim of the treatment was reduction in mean headache frequency and increase in headache-free days.

Mean headache intensity (0-10 scale), duration and frequency were assessed before and 1 week after the procedure. The number of headache-free days was also assessed.

Lidocaine $1 \%(3 \mathrm{ml})$ and triamcinolone $40 \mathrm{mg}$ were injected at the GON ipsilaterally to the side of cluster headache. The patients did not have to have palpable pain over the site of the injection. The GON blockade was defined as the appearance of hypo-anaesthesia in the GON area after the procedure. It was reported by all patients, and lasted $4-8 \mathrm{~h}$ after the procedure.

Clinical response was rated as good (headache free for at least 2 weeks), moderate (headache-free days that lasted $<2$ weeks), and none (no headache-free days). Two patients with episodic cluster headache had their cycle terminated by the nerve block; we estimated the number of headache-free days to be to the expected end of the current cycle. Patients received preventive treatment, but not prednisone.

Wilcoxon signed ranks test was used to compare duration, frequency and intensity before and after the nerve block. $P<0.05$ was considered to be significant. 
Table 1 Age, gender, temporal pattern, clinical response, number of headache-free days after the greater occipital nerve block, mean intensity, frequency and duration before and 1 week after the block

\begin{tabular}{|c|c|c|c|c|c|c|c|c|c|c|c|}
\hline & Age & Gender & $\begin{array}{l}\text { Temporal } \\
\text { pattern }\end{array}$ & $\begin{array}{l}\text { Headache-free } \\
\text { days after }\end{array}$ & Response & $\begin{array}{l}\text { Intensity } \\
\text { before }\end{array}$ & $\begin{array}{l}\text { Intensity } \\
\text { after }\end{array}$ & $\begin{array}{l}\text { Frequency } \\
\text { before }\end{array}$ & $\begin{array}{l}\text { Frequency } \\
\text { (attacks/day) } \\
\text { after }\end{array}$ & $\begin{array}{l}\text { Duration } \\
\text { before }\end{array}$ & $\begin{array}{l}\text { Duration } \\
\text { after }\end{array}$ \\
\hline 1 & 30 & M & E & 0 & $\mathrm{~N}$ & 10 & 10 & 2 & 2 & 60 & 60 \\
\hline 2 & 68 & M & $\mathrm{E}$ & 21 out of cycle & G & 8 & 0 & 2 & 0 & 45 & 0 \\
\hline 3 & 47 & $\mathrm{~F}$ & $\mathrm{C}$ & 0 & $\mathrm{~N}$ & 10 & 7 & 3 & 2 & 40 & 20 \\
\hline 4 & 52 & M & $\mathrm{C}$ & 70 & G & 8 & 0 & 1 & 0 & 30 & 0 \\
\hline 5 & 65 & M & E & 14 out of cycle & G & 10 & 0 & 2 & 0 & 15 & 0 \\
\hline 6 & 29 & M & E & 0 & $\mathrm{~N}$ & 10 & 10 & 4 & 4 & 40 & 40 \\
\hline 7 & 33 & $\mathrm{M}$ & E & 2 & $\mathrm{M}$ & 10 & 7 & 4 & 2 & 45 & 20 \\
\hline 8 & 40 & M & E & 2 & M & 9 & 0 & 2 & $0^{*}$ & 45 & 0 \\
\hline 9 & 36 & M & $\mathrm{E}$ & 4 & M & 9 & 6 & 3 & 1 & 90 & 60 \\
\hline 10 & 53 & $\mathrm{~F}$ & C & 0 & $\mathrm{~N}$ & 10 & 6 & 5 & 1 & 60 & 60 \\
\hline 11 & 40 & M & $\mathrm{C}$ & 3 & M & 8 & 5 & 5 & 1 & 45 & 15 \\
\hline 12 & 38 & M & $\mathrm{C}$ & 64 & G & 9 & 0 & 6 & 0 & 60 & 0 \\
\hline 13 & 69 & M & E & 4 & M & 6 & 0 & 2 & $0^{*}$ & 45 & 0 \\
\hline 14 & 55 & M & $\mathrm{E}$ & 0 & $\mathrm{~N}$ & 10 & 10 & 3 & 3 & 60 & 60 \\
\hline $\begin{array}{l}\text { Mean } \\
\pm S D\end{array}$ & & & & $13.1 \pm 23.6$ & & $9.1 \pm 1.2$ & $4.3 \pm 4.2$ & $3.1 \pm 1.4$ & $1.1 \pm 1.3$ & $48.5 \pm 17.3$ & $23.9 \pm 26.3$ \\
\hline$P$-value & & & & & & & 0.003 & & 0.003 & & 0.005 \\
\hline
\end{tabular}

E, Episodic; C, chronic; G, good; $M$, moderate; N, none.

*Patients 8 and 13 had only one attack, 3 and 5 days after the blockade, respectively.

Table 2 Mean, SD, and range of headache-free days after nerve block, overall, and in the groups with good, moderate and no response

\begin{tabular}{lccc}
\hline Response & Mean (headache-free days) & SD & Range \\
\hline Good & 42.2 & 28.8 & $14-70$ \\
Moderate & 3 & 1 & $2-4$ \\
No response & 0 & 0 & 0 \\
Overall & 13.1 & 23.6 & $0-70$ \\
\hline
\end{tabular}

Mean and standard deviation (SD) were given for the numeric variables.

\section{Results (Tables 1 and 2)}

The response rate was good overall: nine patients $(64 \%)$ had a moderate to good response; four patients $(28.5 \%)$ had a good response, five (35.7\%) moderate, and five $(35.7 \%)$ no response. Two patients (nos 3 and 10) with no headache-free days after the blockade had number of attacks, intensity and duration reduced. The procedure was very well tolerated with no side-effects or complications. Chronic and episodic cluster headache patients responded similarly to nerve block (60\% and $67 \%$ moderate to good response, respectively). Duration, frequency and intensity of attacks, before and 1 week after the nerve block, were significantly lower (duration $48.5+17.3 \mathrm{~min}$ before to $23.9+26.3 \mathrm{~min}$ after; frequency $3.1+1.4$ before to $1.1+1.3$ after; and intensity $9.1+1.2$ before to $4.3+4.2$ after the blockade). The mean number of headache-free days after blockade was 13.1 days.

\section{Discussion}

Transitional cluster therapy is a short-term preventive treatment that bridges the time between cluster diagnosis and the time when the true traditional maintenance preventive agent becomes efficacious. Transitional preventives are started at the same time the traditional preventive is begun. The transitional preventive should provide the cluster patient with almost immediate pain relief and allow the patient to be headache free or near headache free while the traditional preventive medication dose is being increased to an effective level. When the transitional agent is tapered off the maintenance preventive will have kicked in, thus the patient will have no gap in headache preventive coverage.

Our study suggests that GON blockade is an effective transitional treatment for both episodic and chronic cluster headache. Its effect is immediate when it works, which makes it an option to carry out early in treatment. It is simple and can be done by any physician. 
A response to local injections of the GON in cluster was first reported by Anthony, in 1984 (2). He studied episodic and cluster headache patients and found a better response rate than we did. Headache-free days ranged from 5 to 129 days among responders; four (20\%) patients did not respond. Anthony used methylprednisolone $120 \mathrm{mg}$, as opposed to triamcinolone $40 \mathrm{mg}$ in this study.

The episodic nature of cluster headache makes the interpretation of uncontrolled treatments difficult to assess. The two patients who went out of cycle could have done so just by natural history and be unrelated to the GON blockade, although we think the procedure was a possible reason the cycle terminated. Omitting these two episodic cluster patients, the mean headachefree days was 12.4 .

The mechanism of GON block efficacy in cluster headache is unknown. We postulate that the cervical block may affect the spinal trigeminal nucleus, decreasing its sensory input modulating central processes, and thus decreasing trigeminal activity, possibly interrupting the trigeminal autonomic reflex pathway (4). Its short-term relief seen in some patients suggests re-activation of the trigeminal system after wearing off of the blockade, potentially related to continued input from the hypothalamus (5) which would not be affected by the nerve blockade. The use of a systemic corticosteroid could itself be active in the GON blockade, since the use of systemic corticosteroids is a consolidated transitional treatment for cluster headaches (6). GON block is an alternative to the treatment in cluster headache patients.

\section{References}

1 Dodick DW, Rozen TD, Goadsby PJ, Silberstein SD. Cluster headache. Cephalalgia 2000; 20:787-803.

2 Anthony M. Arrest of attacks of cluster headache by local steroid injection of the occipital nerve. In: Rose C, editor. Migraine. Proceedings of the 5th Int Migraine Symposium, London 1984. Basel: Karger, 1985:169-73.

3 Headache Classification Committee of the International Headache Society. Classification and diagnostic criteria for headache disorders, cranial neuralgias and facial pain. Cephalalgia 1988; 8 (Suppl. 7):1-96.

4 Goadsby PJ, Bahra A, May A. Mechanisms of cluster headache. Cephalalgia 1999; 19 (Suppl. 23):19-21.

5 May A, Bahra A, Buchel C, Frackowiak RS, Goadsby PJ. Hypothalamic activation in cluster headache attacks. Lancet 1998; 352 (9124):275-8.

6 Couch JR Jr, Ziegler DK. Prednisone therapy for cluster headache. Headache 1978; 18:219-21. 